\title{
Selection Bias in a Study of Implantable Defibrillator Patients: The Role of Type D Personality
}

\author{
Krista C. van den Broek • Ivan Nyklíček • \\ Johan Denollet
}

Published online: 13 March 2010

(C) The Author(s) 2010. This article is published with open access at Springerlink.com

\begin{abstract}
Background Selection bias constitutes a major issue in research using volunteers as study participants.

Purpose We examined whether research in partners may affect participation rates of implantable cardioverterdefibrillator (ICD) patients with a Type D personality (joint presence of negative affectivity and social inhibition).

Method Patients who underwent ICD implantation between May 2003 and November 2007, and who had a partner, were included $(n=440)$. In September 2005, a substudy on partners of ICD patients was added ( $n=276$ patients).

Results The proportion Type D patients after the start of the partner substudy was significantly lower as compared to the proportion before this substudy $(17.5 \%$ versus $28.8 \%$; $p=$ 0.006). Patients who participated following the start of the partner substudy were less likely to have a Type D personality $(\mathrm{OR}=0.44 ; p=0.002)$, adjusting for possible confounders. In the partner substudy, nonparticipation was more prevalent among partners of Type D patients as compared to partners of non-Type D patients (20.4\% versus $10.1 \% ; p=0.044)$. Partner nonparticipation was marginally significantly associated with Type D personality of the patient $(\mathrm{OR}=2.13 ; p=0.083)$, adjusting for confounders.

Conclusions The addition of a partner substudy may be related to a decreased proportion of participants with a Type $\mathrm{D}$ personality. Nonparticipation was more prevalent among partners of Type D patients. These observations may influence results of studies, as Type Ds tend to be less healthy.
\end{abstract}

Keywords Implantable defibrillator Spouses . Selection bias $\cdot$ Personality

K. C. van den Broek $(\bowtie) \cdot$ I. Nyklíček $\cdot$ J. Denollet CoRPS - Center of Research on Psychology in Somatic diseases, Department of Medical Psychology, Tilburg University, PO Box 901535000 LE, Tilburg, The Netherlands e-mail: CvdBroek@uvt.nl

\section{Introduction}

The psychological impact of cardiac disease and treatment on patients has been studied widely, but relatively little attention has been paid to the psychological effects of disease and treatment on the partners of cardiac patients [1-5]. The number of studies on partners of cardiac patients is increasing, and in this regard, it is important to examine the influence of conducting a partner study on participation rates of patients.

Study participants may systematically differ from nonparticipants. This threat to the internal validity and generalizability of study results is called "selection bias" and constitutes a major issue in research using volunteers as study participants [6]. Nonparticipation or nonresponse exists in different forms and each form may be related to different characteristics $[7,8]$. For instance, potential participants who immediately refuse participation may differ from participants who refuse continuation of the study [7]. These groups may also be different from participants who omit items during the survey [8]. Another form of selection bias may result from the addition of a substudy (for instance, on partners of patients), but to our knowledge, this has not been examined to date.

There are no established risk factors for nonparticipation [9]. Some medical studies found nonparticipants or nonconsenters to be more often female [10-12], older [10], or less healthy [13, 14], while other studies found nonparticipants to be younger $[12,14]$. Personality characteristics may also play an important role in the distinction between participants and nonparticipants. A recent study has shown that participants were significantly lower in neuroticism and higher in conscientiousness, extraversion, and agreeableness compared to nonparticipants [7]. In line with the findings regarding neuroticism and extraversion, Type D personality may also be related to nonparticipation. Type D personality comprises two stable personality traits, that is negative affectivity (the tendency to experience 
negative emotions across time and situations) and social inhibition (the tendency to inhibit self-expression in order to avoid negative reactions from others) [15]. Type Ds are rather reserved in nature, which may augment the probability of refusal to participate compared to the non-Type D patient, especially when the partner is also approached for study participation. Type D personality has been related to morbidity and mortality [16]. Hence, an association between Type D personality and nonparticipation of patients may have important consequences for results and their meaning because research has shown that nonparticipants may be less healthy than participants [7, 13, 14]. For these reasons, it is important to examine the impact of having Type D personality on participation rates.

The aim of this study was twofold: First, to examine whether the addition of a partner substudy was associated with participation rates of ICD patients with a Type D personality. Second, to examine whether Type D personality of patients was associated with participation rates of partners in the partner substudy.

\section{Methods}

\section{Patient Population}

Patients, aged 18-80 years, who underwent ICD implantation in the Catharina Hospital, Eindhoven, The Netherlands and the Amphia Hospital, Breda, The Netherlands between May 2003 and November 2007 were included in a study on personality, anxiety, and person-centered and medical outcomes in ICD patients. Patients were excluded in case of significant cognitive impairments (e.g., dementia), severe life-threatening comorbidities (e.g., cancer), or inability to read and understand Dutch. Only patients with a partner were included for analyses in this particular study.

\section{Partner Substudy}

In September 2005, a substudy on psychological effects of ICD implantation for partners of ICD patients was added. When the patient was informed about the study, he/she was asked whether he/she had a partner. Next, the partner substudy was explained to the patient, and he/she was asked to hand over the study material to the partner, including a form which outlined the study, the informed consent form, and the questionnaire. The patient and partner took all information home and were given a week to decide to participate in the study and complete and return questionnaires. Partners were excluded if the patient declined participation. No further criteria were formulated for the partners.

The later addition of the partner substudy provided us with the opportunity to test differences between patients who were included before the start of the substudy and patients who were included after the start of the substudy. In addition, differences could be examined between patients whose partner participated in the substudy and patients whose partner refused to participate.

Both the main study and the partner substudy were approved by the Medical Ethics Committees of the participating hospitals and were conducted in accordance with the Helsinki Declaration. All patients and partners provided written informed consent.

\section{Demographic Variables}

The demographic patient variables age, gender, and education were included, with low education referring to less than 7 years of education. In addition, clinical patient variables were incorporated, including type of ICD (singleor dual-chamber ICD versus biventricular ICD), ICD indication (primary versus secondary prevention of sudden cardiac death, with primary prevention referring to patients at risk for ventricular arrhythmia and secondary prevention to patients who have experienced ventricular arrhythmia), etiology (ischemic cardiomyopathy versus nonischemic cardiomyopathy), and comorbidity (rheumatic, lung or kidney disease, or diabetes).

\section{Personality}

Between 0 and 3 weeks following ICD implantation, patients completed the 14-item Type D Scale (DS14) to measure Type D personality [15]. The DS14 consists of the 7-item subscales negative affectivity (e.g., "I often feel unhappy") and social inhibition (e.g., "I am a 'closed' person"). Items are answered on a five-point Likert scale ranging from 0 -false to 4-true. Total scores on both subscales range from 0 to 28. Patients scoring high on both subscales; i.e., equal to or above the standardized cutoff score 10, are classified as Type D [15]. These cutoff points have shown to be reliable in discriminating Type Ds from non-Type Ds [17]. Internal consistency is high with Cronbach's $\alpha$ values of 0.88 for negative affectivity and 0.86 for social inhibition [15]. The temporal stability of Type D personality has also been confirmed $[15,18]$.

\section{Emotional Distress}

Patients completed the State-Trait Anxiety Inventory (STAI, form Dutch Y-1) and the Beck Depression Inventory (BDI) at baseline.

The STAI measures general symptoms of state anxiety [19]. Items are scored on a four-point Likert scale ranging from 1-not at all to 4-very much so. Scores range from 20 , i.e., low level of state anxiety to 80 , i.e., high level of 
state anxiety. The STAI has been demonstrated to have adequate validity and reliability, with Cronbach's $\alpha$ ranging from 0.87 to 0.92 .

The BDI is a 21 -item self-report measure developed to assess the presence and severity of depressive symptoms [20]. Each item is rated on a Guttmann scale from 0 to 3 . The BDI is a reliable (Cronbach's $\alpha=0.83$ in this study) and valid measure of depressive symptomatology.

\section{Statistical Analysis}

First, differences in clinical and personality characteristics between patients included after the start of the partner substudy and those included before the start of this substudy were examined by means of chi-square tests and independent $t$ tests. Next, another series of chi-square tests and independent $t$ tests were performed to investigate differences between patients whose partner agreed to participate and patients whose partner declined participation. Subsequently, logistic regression analysis was performed to determine independent associations of Type D personality and demographic and clinical variables with the cohort of patients who were included after the start of the partner substudy. A logistic regression analysis was also applied to determine independent associations between Type D personality and demographic variables and the cohort of patients whose partner did not participate. Clinical variables were not included in these additional analyses. All statistical analyses were performed using SPSS 14.0 for Windows. A $p$ value $<0.05$ was considered to be statistically significant.

\section{Results}

\section{Patient and Partner Characteristics}

Of the 513 patients who agreed to participate in the study, six patients had to be excluded due to missing data on Type D personality $(n=4)$ or smoking $(n=2)$, resulting in a sample of 507 ICD patients, of which $440(86.8 \%)$ had a partner. Of these 440 patients, $21.6 \%(n=95)$ was classified as Type $\mathrm{D}$, $82.5 \%(n=363)$ was male, $21.6 \%(n=95)$ had less than 7 years of education, $58.2 \%(n=256)$ had a primary ICD indication, $73.0 \%(n=321)$ had ischemic cardiomyopathy, $30.7 \%(n=135)$ had a biventricular ICD, and $37.0 \%(n=163)$ were suffering from comorbidities. The mean age of these patients was 62.6 years $(\mathrm{SD}=9.7$, range $28-79)$.

Of 440 patients who had a partner, 276 patients $(62.7 \%)$ were included after the start of the partner substudy. Of 276 potential partners, $243(88.0 \%)$ participated; the mean age in this sample of 243 partners was 60.3 years $(\mathrm{SD}=9.4)$ and 45 partners $(18.4 \%)$ were male.

\section{Patient Participation following Start Partner Substudy}

First, differences between patients included before $(n=$ $160)$ and after $(n=280)$ the partner substudy were investigated. The proportion of Type D patients included after the start of the partner substudy was significantly lower compared to the proportion before the start of this substudy $\left(17.5 \%\right.$ versus $\left.28.8 \%, \chi^{2}(1)=7.6, p=0.006\right)$, suggesting a decreased participation rate of Type $D$ patients following the addition of the partner substudy (Fig. 1). In addition, patients included after addition of the partner substudy more often had primary prevention $(p<$ 0.001 ) as compared to patients included before the start of the substudy (Table 1).

Multivariable logistic regression analysis showed that patients included during the partner substudy were less likely to have a Type $D$ personality $(O R=0.44)$ as compared to the proportion of Type Ds before the start of the substudy, when controlling for other variables (Table 2). This indicates that the reduction in the proportion of Type D patients after the start of the partner substudy was not a function of other patient characteristics. Patient participation after the start of the partner substudy was also independently associated with primary ICD indication $(\mathrm{OR}=6.00)$ and inversely with having a biventricular ICD $(\mathrm{OR}=0.44)$. Age, gender, education, etiology, and comorbidities were not significant in this model.

In secondary analyses, we investigated whether the lower prevalence of Type D patients in the group of patients included after the start of the partner substudy would correspond with lower distress levels in this group. Anxiety levels in patients included after the start of the partner substudy were indeed lower as compared to levels of patient included before $(37.7 \pm 11.5$ versus $40.6 \pm 12.1, t(435)=2.5$, $p=0.012$ ). Similar results were found for depression levels $(8.2 \pm 6.3$ versus $9.0 \pm 7.0, t(438)=1.3, p=0.20)$, although the difference in mean levels was not statistically significant.

Fig. 1 Percentage of patients with a Type $\mathrm{D}$ personality before and after the start of the partner substudy

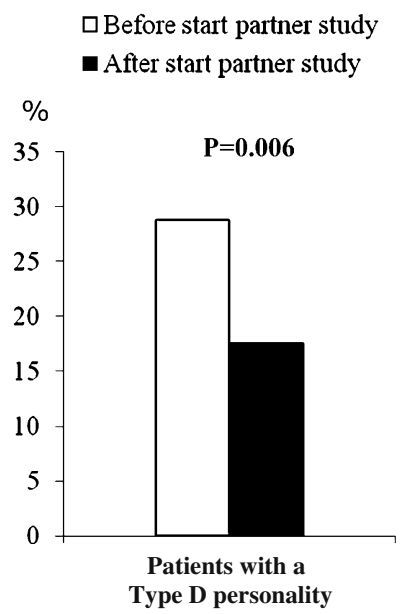


Table 1 Characteristics of patients included before and after the start of the partner substudy $(n=440)$

${ }^{\mathrm{a}}$ Univariate analysis (chi-square tests and independent $t$ tests)

\begin{tabular}{llll}
\hline Patient variables & $\begin{array}{l}\text { Before start substudy }(n=160) \\
\%(n)\end{array}$ & $\begin{array}{l}\text { After start substudy }(n=280) \\
\%(n)\end{array}$ & $p^{\mathrm{a}}$ \\
\hline $\begin{array}{l}\text { Demographic variables } \\
\text { Age (mean } \pm \mathrm{SD})\end{array}$ & $M=61.6 \pm 10.4$ & $M=63.1 \pm 9.2$ & 0.13 \\
Female gender & $14.4 \%(23)$ & $19.3 \%(54)$ & 0.19 \\
Low education & $21.9 \%(35)$ & $21.4 \%(60)$ & 0.91 \\
Clinical variables & & & $<0.001$ \\
Primary prevention & $35.6 \%(57)$ & $71.1 \%(199)$ & 0.24 \\
Ischemic cardiomyopathy & $76.3 \%(122)$ & $71.1 \%(199)$ & 0.82 \\
Biventricular ICD & $30.0 \%(48)$ & $31.1 \%(87)$ & 0.057 \\
Comorbidity & $31.3 \%(50)$ & $40.4 \%(113)$ & \\
\hline
\end{tabular}

When adjusting for clinical factors, these results did not change. These findings indicate that the decreased prevalence of Type D personality affects distress levels, with lower distress levels being found in the group with lower Type D prevalence, independent of clinical variables.

Partner Nonparticipation in the Substudy

Selection bias was also investigated in partners who participated in the study $(n=243)$ versus partners who did not participate in the study $(n=33)$. Chi-square analysis showed that nonparticipation was more prevalent among partners of Type D patients as compared to partners of non-Type D patients $(20.4 \%$ versus $10.1 \%$; $p=0.044$; Fig. 2$)$. In addition, $9.4 \%$ of the partners did not participate if the patient was male versus $22.6 \%$ if the patient was female $(p=0.008)$.

Multivariable logistic regression analysis (Table 3 ) showed that female gender of the patient was the only variable which was independently associated with a 2.9-fold risk of nonparticipation of partners. In addition, there was a trend for Type $D$ personality of the patient $(O R=2.13)$ to be associated with nonparticipation of the partner. Age and education of the patient were not significantly related to partner nonparticipation.

\section{Discussion}

This study investigated the (a) associations of Type D personality and demographic and clinical variables of ICD patients with their participation rate in research either involving or not involving additional participation of their partners and (b) associations of Type D personality and demographic variables of the patient with nonparticipation rates of their partners. We found that patients who participated following the start of the partner substudy were significantly less likely to have a Type D personality and biventricular ICD and significantly more likely to have primary prevention and comorbidities. This group also reported less emotional distress than the patients included before the start of the partner substudy. Partner nonparticipation was more prevalent among partners of female patients and tended to be more prevalent in partners of Type D patients. Hence, the addition of a substudy on
Table 2 Characteristics of patients included after the start of the partner substudy $(n=440)$

${ }^{a}$ Patients included after the start of the partner substudy coded as 1

\begin{tabular}{|c|c|c|c|}
\hline \multirow[t]{2}{*}{ Patient variables } & \multicolumn{3}{|c|}{ Multivariable logistic regression analysis ${ }^{\mathrm{a}}$} \\
\hline & OR & $95 \% \mathrm{CI}$ & $p$ \\
\hline \multicolumn{4}{|l|}{ Personality } \\
\hline Type D personality & 0.44 & $0.26-0.75$ & 0.002 \\
\hline \multicolumn{4}{|l|}{ Demographic variables } \\
\hline Age & 1.02 & $1.00-1.04$ & 0.17 \\
\hline Female gender & 1.52 & $0.83-2.79$ & 0.17 \\
\hline Low education & 1.09 & $0.64-1.85$ & 0.76 \\
\hline \multicolumn{4}{|l|}{ Clinical variables } \\
\hline Primary prevention & 6.00 & $3.72-9.67$ & $<0.001$ \\
\hline Ischemic cardiomyopathy & 0.62 & $0.37-1.05$ & 0.075 \\
\hline Biventricular ICD & 0.44 & $0.26-0.74$ & 0.002 \\
\hline Comorbidity & 1.56 & $0.98-2.48$ & 0.060 \\
\hline
\end{tabular}


Fig. 2 Percentage of nonparticipating partners as a function of Type D personality of the patient $\square$ Non-Type $\mathrm{D}$ patient

-Type D patient

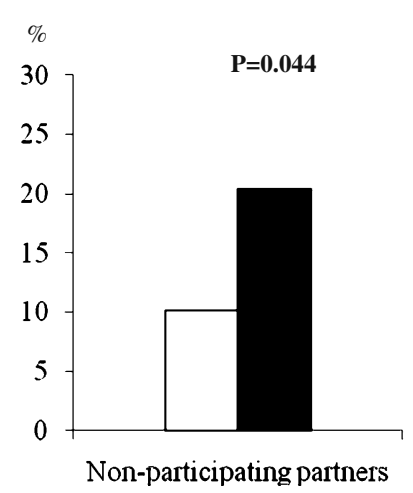

partners of ICD patients may have resulted in selection bias related to the personality of the patients in two different ways. This may have affected distress levels.

To our knowledge, no other studies have reported on nonparticipation following addition of a partner study. In addition, we can only speculate why the prevalence of Type D personality significantly decreased after the addition of a substudy on partners. Type D patients are closed persons and want to keep people at a distance, in combination with a tendency to experience high negative affect [15]. It may be speculated that because of this combination, they are more reluctant to cooperate in a study which may trigger their partner to encourage the patient to disclose about their negative feelings. As the patients' cooperation was also needed in asking the partner to participate, this also may have influenced the participation rates of their partners.

In this study, the Type D personality may have played an important role for selection bias. Participants and nonparticipants may also differ on a number of characteristics related to personality traits, including their psychological and physical health; that is, participants may be more psychologically adapted (e.g., lower in neuroticism and higher in conscientiousness) and may therefore be healthier than nonparticipants [7]. In patients with coronary heart disease, Type D personality has been associated with clinical outcomes, such as an increased risk for morbidity and mortality [16]. As a consequence, selection bias may result in an underrepresentation of Type $D$ patients and therefore an overrepresentation of healthy participants. Our results supported this line of reasoning, as distress levels were lower in the group of patients with a lower prevalence of Type D personality. These effects imply potentially important consequences for study results.

ICD indication is being incorporated in most studies on ICD patients. In recent years, guidelines for ICD implantation have been expanded, particularly regarding primary prevention of sudden cardiac death [21]. Therefore, the significant effect of primary prevention for patients included after the partner substudy was expected. We had no specific prospects regarding etiology, having a biventricular ICD, or comorbidities, but these characteristics were (marginally) significantly related to inclusion after the start of the partner substudy.

Some of the demographic covariables were also significantly associated with study participation. Male partners more often did not participate as compared to female partners, which contradicts results of previous studies [10$12]$, but is important to take into account when performing substudies involving partners of (ICD) patients.

The results of this study should be interpreted with caution. Our study includes ICD patients only. Generalizability to other populations is therefore limited. In addition, no data were available on patients who were invited to participate but declined. This group may contain a high percentage of Type D patients, but this prevalence is hard to determine, since Medical Ethics Committees will not easily approve a proposition to provide patients, who declined participation immediately, with a questionnaire. Nevertheless, the present study reveals important information on the association of Type D personality with participation rates, when adding a partner substudy to the main study. Given that a better comprehension of the interpersonal context of Type D patients is important [22], the results of the current study should be taken into account in future studies.

Table 3 Participating versus nonparticipating partners as a function of patient characteristics $(n=276)$

\begin{tabular}{|c|c|c|c|c|c|}
\hline \multirow[t]{2}{*}{ Patient variables } & \multirow{2}{*}{$\begin{array}{l}\text { Participating partners }(n=243) \\
\%(n)\end{array}$} & \multirow{2}{*}{$\begin{array}{l}\text { Nonparticipating partners }(n=33) \\
\%(n)\end{array}$} & \multicolumn{3}{|c|}{ Multivariable logistic regression analysis ${ }^{a}$} \\
\hline & & & OR & $95 \% \mathrm{CI}$ & $p$ \\
\hline \multicolumn{6}{|l|}{ Personality patient } \\
\hline Type D personality & $16.0 \%(39)$ & $30.3 \%(10)$ & 2.13 & $0.91-5.00$ & 0.083 \\
\hline \multicolumn{6}{|l|}{ Demographic variables } \\
\hline Age (patient); mean $\pm \mathrm{SD}$ & $M=63.0 \pm 9.0$ & $M=64.3 \pm 10.5$ & 1.03 & $0.99-1.07$ & 0.20 \\
\hline Female gender (patient) & $16.9 \%(41)$ & $36.4 \%(12)$ & 2.92 & $1.29-6.61$ & 0.010 \\
\hline Low education (patient) & $21.4 \%(52)$ & $24.2 \%(8)$ & 0.89 & $0.36-2.21$ & 0.81 \\
\hline
\end{tabular}

${ }^{a}$ Nonparticipation of partner coded as 1 
Investigating partner issues is valuable as results show that partners of chronically ill patients, including ICD patients, experience as much distress as patients themselves [1, 3-5]. In future studies, strategies need to be applied to also include a representative number of Type D patients in such studies. It may be particularly important that inclusion for the study is performed by a supportive person, who is (preferably) known by the Type D patient, such as an ICD nurse. This nurse may have several conversations with the Type D patient to explain the study, such that the patient gets familiar with the nurse and the study and may feel more comfortable in participating. Emphasizing individuality (that is, the patient does not have to discuss answers with his/her partner) and anonymity in answering questionnaires may also be important.

In conclusion, in the ICD population, the addition of a partner substudy was related to a decreased proportion of participating patients with a Type D personality and with a decreased level of emotional distress. Also, nonparticipation of partners was more prevalent among partners of Type D patients as compared to partners of non-Type D patients. These effects should be considered when planning a partner substudy. In general, it is important for researchers to consider possible bias by introducing new elements to the main study that may affect participation rates and emotional distress levels.

Acknowledgments This study was supported by the Netherlands Organization for Scientific Research, The Hague, The Netherlands with a VICI grant (453-04-004) to Dr. Johan Denollet.

We would like to thank Eefje Postelmans for inclusion of the patients into the study and Martha van den Berg (MSc), Vivianne Sterk (MSc), Jolien Diekhorst (MSc), Marjan Traa (MSc), and Marie-Anne Mittelhaeuser (BSc) for their help with data management.

Conflict of interest No authors have any conflict of interest.

Open Access This article is distributed under the terms of the Creative Common Attribution Noncommercial License which permits any noncommercial use, distribution, and reproduction in any medium, provided the original author(s) and source are credited.

\section{References}

1. Pedersen SS, van Domburg RT, Theuns DA, Jordaens L, Erdman RA. Type D personality is associated with increased anxiety and depressive symptoms in patients with an implantable cardioverter defibrillator and their partners. Psychosom Med. 2004;66:714-9.

2. Luttik ML, Blaauwbroek A, Dijker A, Jaarsma T. Living with heart failure: partner perspectives. J Cardiovasc Nurs. 2007;22:131-7.

3. Moser DK, Dracup K. Role of spousal anxiety and depression in patients' psychosocial recovery after a cardiac event. Psychosom Med. 2004;66:527-32.

4. Pedersen SS, Van den Berg M, Erdman RA, van Son J, Jordaens L, Theuns DA. Increased anxiety in partners of patients with a cardioverter-defibrillator: the role of indication for ICD therapy, shocks, and personality. Pacing Clin Electrophysiol. 2009;32:184-92.

5. Sowell LV, Sears Jr SF, Walker RL, Kuhl EA, Conti JB. Anxiety and marital adjustment in patients with implantable cardioverter defibrillator and their spouses. J Cardiopulm Rehabil. 2007;27:46-9.

6. Hartge P. Participation in population studies. Epidemiology. 2006;17:252-4.

7. Lonnqvist JE, Paunonen S, Verkasalo M, Leikas S, TuulioHenriksson A, Lonnqvist J. Personality characteristics of research volunteers. Eur J Pers. 2007;21:1017-30.

8. Marcus B, Schutz A. Who are the people reluctant to participate in research? Personality correlates of four different types of nonresponse as inferred from self- and observer ratings. J Pers. 2005;73:959-84.

9. Morton LM, Cahill J, Hartge P. Reporting participation in epidemiologic studies: a survey of practice. Am J Epidemiol. 2006;163:197-203.

10. Ramos E, Lopes C, Barros H. Investigating the effect of nonparticipation using a population-based case-control study on myocardial infarction. Ann Epidemiol. 2004;14:437-41.

11. Buckley B, Murphy AW, Glynn L, Hennigan C. Selection bias in enrollment to a programme aimed at the secondary prevention of ischaemic heart disease in general practice: a cohort study. Int J Clin Pract. 2007;61:1767-72.

12. Jacobsen SJ, Xia Z, Campion ME, et al. Potential effect of authorization bias on medical record research. Mayo Clin Proc. 1999;74:330-8.

13. Al-Shahi R, Vousden C, Warlow C. Bias from requiring explicit consent from all participants in observational research: prospective, population based study. BMJ. 2005;331:942.

14. Oleske DM, Kwasny MM, Lavender SA, Andersson GB. Participation in occupational health longitudinal studies: predictors of missed visits and dropouts. Ann Epidemiol. 2007;17: 9-18.

15. Denollet J. DS14: standard assessment of negative affectivity, social inhibition, and Type D personality. Psychosom Med. 2005;67:89-97.

16. Pedersen SS, Denollet J. Is Type D personality here to stay? Emerging evidence across cardiovascular disease patient groups. Curr Cardiol Rev. 2006;2:205-13.

17. Emons WH, Meijer RR, Denollet J. Negative affectivity and social inhibition in cardiovascular disease: evaluating Type D personality and its assessment using item response theory. J Psychosom Res. 2007;63:27-39.

18. Martens EJ, Kupper N, Pedersen SS, Aquarius AE, Denollet J. Type D personality is a stable taxonomy in post-MI patients over an 18-month period. J Psychosom Res. 2007;63:545-50.

19. Van der Ploeg HM, Defares PB, Spielberger CD (1980) [Handleiding bij de Zelf-Beoordelings Vragenlijst (ZBV). Een nederlandstalige bewerking van de Spielberger State-Trait Anxiety Inventory]. Manual for the ZBV. A Dutch-language adaptation of the Spielberger State-Trait Anxiety Inventory. Lisse: Swets \& Zeitlinger B.V.; The Netherlands

20. Beck AT, Steer RA (1993) Manual for the revised Beck Depression Inventory

21. Gregoratos G, Abrams J, Epstein AE, et al. ACC/AHA/NASPE 2002 guideline update for implantation of cardiac pacemakers and antiarrhythmia devices: summary article: a report of the American College of Cardiology/American Heart Association Task Force on Practice Guidelines (ACC/AHA/NASPE Committee to Update the 1998 Pacemaker Guidelines). Circulation. 2002;106:2145-61.

22. Steptoe A, Molloy GJ. Personality and heart disease. Heart. 2007;93:783-4. 